\title{
Nanometer-scale dynamics of high-temperature levitated liquids
}

\author{
D.L.Price ${ }^{1}$, L. Hennet ${ }^{1}$, I.Pozdnyakova ${ }^{1}$, M.-L.Saboungi ${ }^{2}$ \\ ${ }^{1}$ Centre de Recherche sur les Matériaux à Haute Température, $1 \mathrm{~d}$ avenue de la Recherche Scientifique, \\ 45071 Orléans cedex 2, France \\ 2 Centre de Recherche sur la Matière Divisée, $1 \mathrm{~b}$ rue de la Férollerie, 45071 Orléans cedex 2, France
}

Received November 16, 2007

We review recent measurements of the microscopic dynamics of high-temperature liquids made with inelastic $\mathrm{x}$-ray scattering and aerodynamic levitation of the samples. Phenomenological and theoretical interpretations are also discussed.

Key words: liquid dynamics, molten oxides, liquid metals, inelastic $x$-ray scattering, aerodynamic levitation

PACS: $66.20 .+d, 61.10 . E q$

\section{Introduction}

The origin of the high-frequency collective excitations in disordered systems is an open issue in condensed matter physics. Usually the evolution of the high-frequency density fluctuations is described by a generalized Langevin equation combined with a memory function formalism, which constitutes extended or generalized hydrodynamics $[1,2]$. The memory function allows for correlation effects in the random force affecting the liquid particle and contains information about the system's transport properties. The thermal fluctuations are separated from longitudinal density fluctuations, and the latter consist of two different decay channels: slow, responsible for structural relaxation, and fast, corresponding to the interactions of an atom with its nearest neighbours [3]. This phenomenological approach was found to work well for several systems, including liquid metals [3], hydrogen-bonded liquids (water [4] and hydrogen fluoride [5]), and noble gases [6].

Experimental studies on high-temperature molten materials are difficult because of the lack of suitable containers, problems of contamination of hot and often reactive liquids by the container material, and difficulties in correcting the scattering signal for the container scattering and absorption. However, more experimental information about complex liquids is desirable in order to establish universal mechanisms that govern the behaviour of liquids at the interface between purely hydrodynamic and kinetic regimes, where a rigorous theoretical description is lacking. To access extremely high temperatures, a containerless environment is used. Aerodynamic levitation combined with laser heating has proved to be a powerful and versatile tool for studying the structure of high-temperature oxide liquids $[7,8]$, and has recently been extended to the study of the dynamics of high-temperature liquids with inelastic x-ray scattering (IXS) [9]. In this article we review the published work to date on the dynamics of levitated molten materials.

*Email: price@cnrs-orleans.fr 


\section{Experimental techniques}

\subsection{Aerodynamic levitation and heating system}

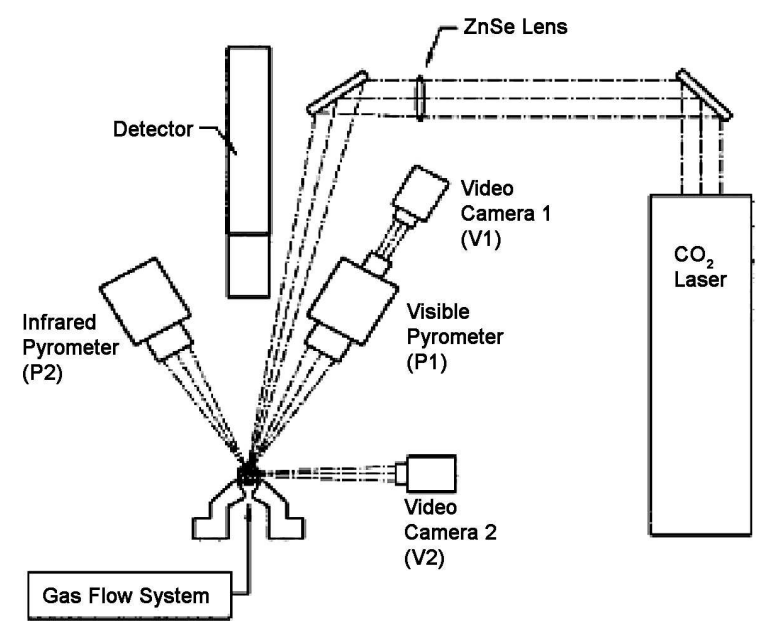

Figure 1. Schematic view of conical nozzle levitation apparatus used for measurements of liquid structure and dynamics [7].
The work performed so far in this field has been carried out with aerodynamic levitation, using the conical nozzle levitation (CNL) technique, in which samples are stably levitated by gas flow in a convergent-divergent nozzle, following which they can be heated to temperatures in excess of $2500 \mathrm{~K}$ with a laser or $\mathrm{RF}$ heating system. A typical CNL system, developed at Containerless Research Inc. (CRI), Evanston, USA [7], is schematically illustrated in figure 1 . In the setup shown here the levitation system is combined with laser heating and integrated with an x-ray goniometer for diffraction experiments at a synchtrotron source. The figure shows all of the key components including two pyrometers, two video cameras and video microscope, curved beryllium window, six-circle goniometer and xray detector. The levitation chamber is lo-

cated at the centre of the goniometer. The heating laser is inclined at $15^{\circ}$ with respect to the normal to avoid physical interference with the x-ray detector. A similar system was developed independently at the Centre de Recherche sur les Matériaux à Hautes Températures (CRMHT), Orléans, France [8].

\subsection{Inelastic $x$-ray scattering}

Inelastic x-ray scattering (IXS) is an ideal tool for studying the dynamics of liquids and amorphous materials with high sound velocities over a broad range of scattering vectors $Q$ in the $\mathrm{nm}^{-1}$ region. Since the high-temperature regime is inaccessible by Brillouin light scattering (the inelastic

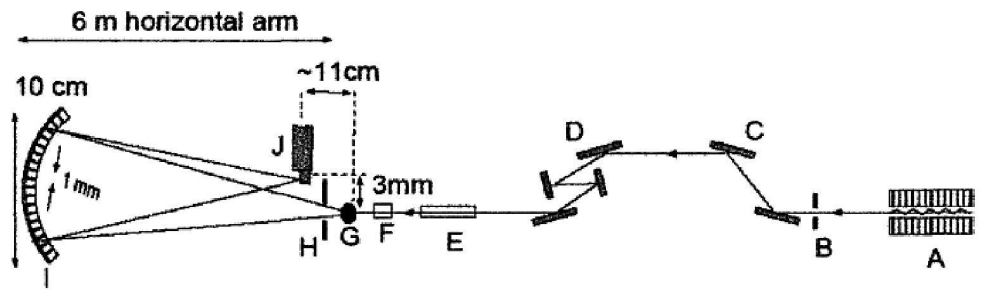

Figure 2. A schematic view of the spectrometer developed at beam line 3-ID at the Advanced Photon Source. The X-ray beam comes from an undulator (A) and pre-monochromator (C), and then passes through the high-resolution monochromator (D) and focusing mirror (E) before it illuminates the sample $(G)$. The scattered intensity is energy analyzed and focused back by crystal analyzer (I) into detector $(\mathrm{J})$. The ionization chamber to monitor the incident flux onto sample is (F). The slit systems that determine the source size are (B) and (H) [13].

signal is obscured by thermal radiation), IXS is the only technique that allows us to simultaneously measure the elastic response and transport properties of refractory melts. Inelastic neutron scattering measurements would also be extremely interesting [10], but so far these have not been feasible in CNL experiments due to the relatively low sample volumes. IXS has become a powerful tool for 
studying the liquid dynamics due to the development of extremely high-resolution monochromators at third-generation synchtrotron sources, combined with back-scattering analyzer geometry $[11,12]$. The IXS spectrometer developed at beam line 3-ID at the Advanced Photon Source, Argonne, USA, is shown schematically in figure 2 [13]. The need to have sample and detector in close proximity to maintain the back-scattering geometry presents a special challenge in studying high-temperature samples with IXS.

\section{Theoretical background}

The intensity measured in an inelastic scattering experiment is related to the classical scattering function $S(Q, \omega)[14]$ :

$$
I(Q, \omega) \propto \mathrm{e}^{\frac{\hbar \omega}{2 k T}} S(Q, \omega) \otimes R(\omega),
$$

where $R(\omega)$ is the energy resolution function of the spectrometer. In a multi-atomic system, the $S(Q, \omega)$ in equation (1) is in fact a weighted average of the partial functions for all the atom pairs. Since the measurements made so far have been either on monatomic systems or ionic liquids in which the atomic numbers $\left(\mathrm{Al}^{3+}, \mathrm{O}^{2-}\right.$, and $\left.\mathrm{Mg}^{2+}\right)$ are similar, so that this average comes close to the function $S_{\mathrm{NN}}(Q, \omega)$ representing number density correlations, we use expressions appropriate to monatomic systems.

The data are analyzed using a memory function approach that works well for several simple liquids. From the generalized Langevin equation, it is possible to express $S(Q, \omega)$ in terms of the real and imaginary parts of the Fourier-Laplace transform of a complex memory function $M(Q, t)$ that contains the information about the transport properties:

$$
S(Q, \omega)=\frac{S(Q) \pi^{-1} \omega_{0}^{2}(Q) \tilde{M}^{\prime}(Q, \omega)}{\left[\omega^{2}-\omega_{0}^{2}(Q)+\omega \tilde{M}^{\prime \prime}(Q, \omega)\right]^{2}+\left[\omega \tilde{M}^{\prime}(Q, \omega)\right]^{2}},
$$

where $\omega_{0}^{2}=k_{\mathrm{B}} T Q^{2} / m S(Q)$ is the second frequency moment of $S(Q, \omega)$ and $m$ the atomic mass. The quantity $\omega_{0}$ is related to the isothermal sound velocity $[2] c_{t}(Q)=\omega_{0}(Q) / Q$ and can be calculated either from the experimental liquid structure factor $S(Q)$ or from the fitting parameters in equation (2) using the expression for $\omega_{0}$ given above.

In the hydrodynamic region $M(Q, t)$ reflects two physically distinct processes: density fluctuations that give rise to sound waves that appear as "Brillouin" side peaks in $S(Q, \omega)$, and entropy fluctuations that give rise to non-propagating excitations that appear as a "Rayleigh" central peak. The ratio of the central peak intensity to the total intensity $S(Q)$ is given by $(\gamma-1) / \gamma$, where $\gamma=C_{p} / C_{v}$, the ratio of specific heats. In the $Q$ region $\left(\sim \mathrm{nm}^{-1}\right)$ that we are dealing with here, it is found that the central peak intensity ratio is much higher than this, and furthermore even for insulating liquids such as $\mathrm{Al}_{2} \mathrm{O}_{3}$ the width of the central peak is several orders smaller than the hydrodynamic value $\left(D_{\mathrm{T}} Q^{2}\right.$ where $D_{\mathrm{T}}$ is the thermal diffusivity). Consequently, it is usual to neglect the entropy fluctuations and treat the central peak observed as a consequence of high damping associated with the density fluctuations [15]. The density fluctuations are then described by a memory function containing two contributions: a slow component following a Debye law related to structural relaxation involving cooperative movements of a larger number of particles, and a fast component associated with the interactions between an atom and the cage of its nearest neighbours that is effectively instantaneous on the time scale (ps) of these measurements:

$$
M(Q, t)=\Delta^{2}(Q) \mathrm{e}^{-t / \tau(Q)}+2 \Gamma_{\mathrm{S}}(Q) \delta(t),
$$

which has the Fourier-Laplace transform

$$
\tilde{M}(Q, \omega)=\frac{\Delta^{2}(Q) \tau(Q)}{1+\mathrm{i} \omega \tau(Q)}+\Gamma_{\mathrm{S}}(Q) .
$$

In equations (3)-(4), $\tau$ is the relaxation time and $\Delta$ is the relaxation strength of the slow component, now related to the Rayleigh peak, and $\Gamma_{\mathrm{s}}$ is the damping coefficient of the fast component, 
related to the Brillouin peak. Equations (3)-(4) represent a phenomenological "viscoelastic" model that, with the fitting parameters $\Gamma_{\mathrm{s}}(Q), \Delta^{2}(Q)$ and $\tau(Q)$, along with the $\omega_{0}(Q)$ introduced above, has been found to fit the IXS spectra for a wide range of liquids.

The excitation frequencies of the liquid are obtained by renormalizing the second moment with the relaxation strength of the slow component [16]:

$$
\Omega_{\mathrm{s}}(Q)=\sqrt{\omega_{0}^{2}(Q)+\Delta^{2}(Q)} .
$$

The longitudinal sound velocity is then given by $c_{\infty}=\lim _{Q \rightarrow 0} \Omega_{\mathrm{S}}(Q) / Q$. Finally, the generalized $Q$-dependent longitudinal viscosity, $\eta_{1}(Q)$, can be extracted from the memory function parameters by:

$$
\eta_{1}(Q)=\frac{\rho\left[\Delta^{2}(Q) \tau(Q)+\Gamma_{\mathrm{S}}(Q)\right]}{Q^{2}} .
$$

At larger $Q$, the central peak widths are expected to be similar in magnitude to those obtained from the single-particle diffusion description, $\Gamma(Q)=D Q^{2}$ where $D$ is the single-particle diffusion constant. A quantitative estimate is given by kinetic theory [17]:

$$
\Gamma(Q)=\frac{D Q^{2}}{S(Q)\left[1-j_{0}(\sigma Q)+2 j_{2}(\sigma Q)\right]},
$$

where $\sigma$ is a characteristic interatomic distance and the $j_{n}(x)$ are Bessel functions.

\section{Liquid oxides}

Besides their fundamental interest, there are also significant practical reasons for studying oxide melts. MgO- and $\mathrm{Al}_{2} \mathrm{O}_{3}$-containing refractory oxides are among the building blocks of the Earth's mantle. Due to their stability under irradiation, high melting point and high thermal conductivity, these materials are being considered as inert matrices for nuclear waste confinement. Knowledge of the elastic and transport properties of those high-temperature liquids is therefore important for a variety of applications, including geophysics, nuclear physics, materials and ceramics sciences. In these materials, the electrical conduction is primarily ionic rather than electronic[18].

\subsection{Liquid $\mathrm{Al}_{2} \mathrm{O}_{3}$}

Liquid aluminium oxide was the first levitated liquid to be studied by IXS (Sinn et al., [9]), chosen because many of its physical properties and structure had been determined in the molten and supercooled states $[8,19,20] . \mathrm{Al}_{2} \mathrm{O}_{3}$ spheres $3-4 \mathrm{~mm}$ in diameter were suspended in an oxygen gas jet and heated with a $270-\mathrm{W} \mathrm{CO}_{2}$ laser beam to temperatures between 2300 and $3100 \mathrm{~K}$. The IXS measurements were carried out at the 3ID-C beam line at the Advanced Photon Source, with an in-line monochromator consisting of two nested channel-cut crystals and a back-scattering analyzer set-up in the horizontal scattering plane at a distance of $6 \mathrm{~m}$ from the sample [13]. The x-ray energy of $21.7 \mathrm{keV}$ corresponded to an $(18,6,0)$ reflection for $\mathrm{Si}$, and the energy resolution was determined from a Plexiglas sample to be $1.8 \mathrm{meV}$ full width at half-maximum. The levitation apparatus was enclosed in a bell jar designed for back-scattering geometry with a separation of 10 $\mathrm{cm}$ between sample and detector. Data were collected over the energy transfer $(\eta \omega)$ range -30 to $60 \mathrm{meV}$ at six values of $Q$, covering the range $1.09-6.09 \mathrm{~nm}^{-1}$, and over a more restricted range $(-30$ to $30 \mathrm{meV})$ covering the central peak for $Q$ 's out to $28 \mathrm{~nm}^{-1}$.

IXS spectra measured at the lowest six $Q$ values at $2323 \mathrm{~K}$ are shown in figure 3 . The spectra are fitted with a three-Lorentzian model that corresponds to the low- $Q$ limit of equation (2), convolved with the resolution function as in equation (1). The values of $\Omega_{\mathrm{s}}(Q)$, calculated in this case from $\Omega_{\mathrm{s}}(Q)=\sqrt{\omega_{\mathrm{s}}^{2}(Q)+\Gamma_{\mathrm{s}}^{2}(Q)}$, where $\omega_{\mathrm{s}}(Q)$ and $\Gamma_{\mathrm{s}}(Q)$ are the position and half-width of the Lorentzian fit to the Brillouin peaks, and $\Gamma_{\mathrm{s}}(Q)$ are plotted in figure 4 , where $\Omega_{\mathrm{s}}$ is seen to be linear in $Q$, corresponding to a longitudinal sound velocity $c_{\infty}=7350 \pm 40 \mathrm{~m} / \mathrm{s}$. This velocity is considerably smaller than that of solid $\alpha$-alumina at room temperature, $10,500 \mathrm{~m} / \mathrm{s}[21]$ : the change on 


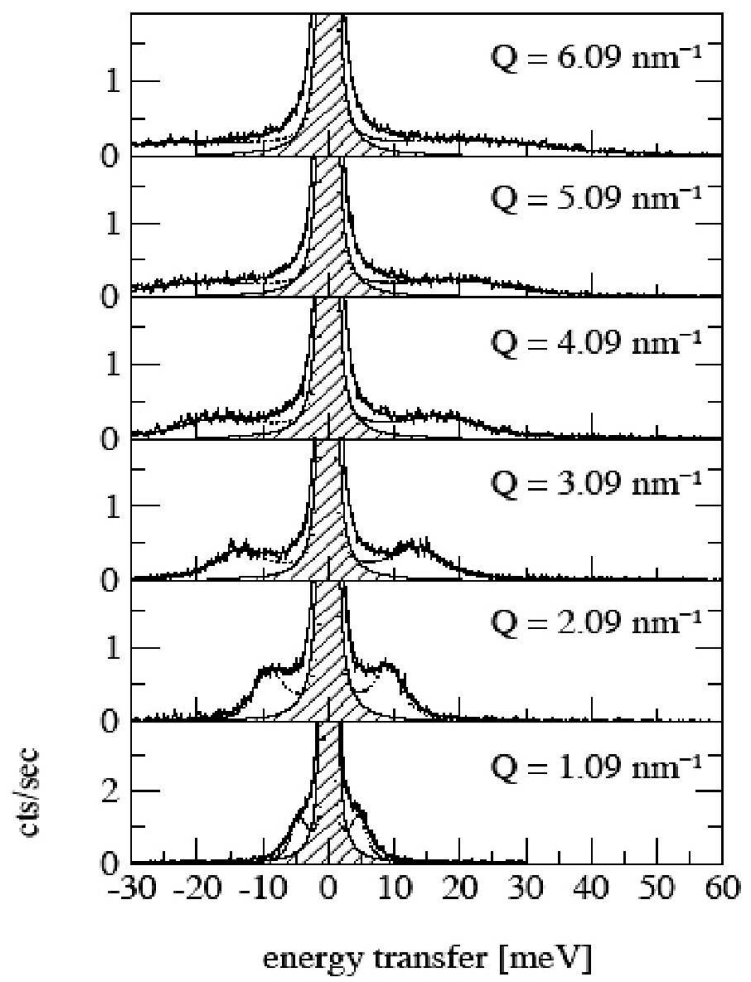

Figure 3. Inelastic x-ray scattering spectra, $I(Q, \omega)$, for liquid $\mathrm{Al}_{2} \mathrm{O}_{3}$ at the 6 lowest wave vectors measured and a temperature of $2323 \mathrm{~K}$. The fits of equations (1), (2) are shown as solid lines and the equivalent functions with the resolution function de-convoluted as dotted lines. The resolution function is shown hatched [9].

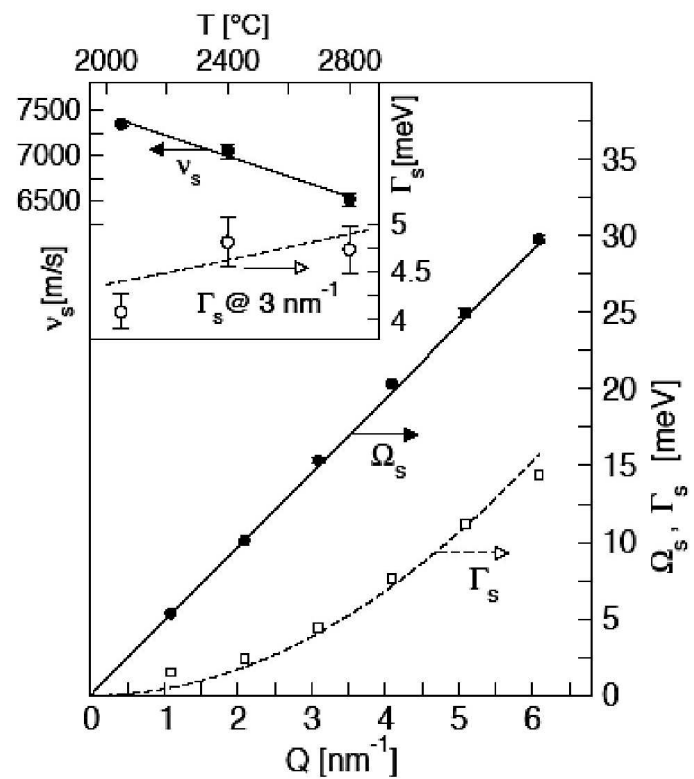

Figure 4. Dependence on wave vector $Q$ of the frequency $\Omega_{\mathrm{s}}$ and half-width $\Gamma_{\mathrm{s}}$ of the Brillouin peaks at $2323 \mathrm{~K}$. The solid line represents $\Omega_{\mathrm{s}}=v_{\mathrm{s}} Q$ with $v_{s}=7350 \mathrm{~m} / \mathrm{s}$ and the dashed line represents $\Gamma_{s}=\alpha Q^{2}$ with $\alpha=6 \cdot 2 \cdot 10^{-7} \mathrm{~m}^{2} / \mathrm{s}$. Inset: temperature dependence of $v_{s}=\Omega_{\mathrm{s}} / Q$ and $\Gamma_{\mathrm{s}}[9]$. 
melting is consistent with those in coordination number [8,19,20], entropy [22] and conductivity [18]. With increasing temperature (inset to figure 4) the value of $c_{\infty}$ falls to $6530 \pm 70 \mathrm{~m} / \mathrm{s}$ at $3073 \mathrm{~K}$.

The Brillouin modes remain under-damped $\left(\Gamma_{\mathrm{s}} / \Omega_{s}<0.5\right.$ out to $Q=6 \mathrm{~nm}^{-1}$, a surprising result for excitations of short wavelength $(\sim 1 \mathrm{~nm})$ in this relatively viscous liquid. The damping coefficient $\Gamma_{\mathrm{s}}$ (figure 4) exhibits a quadratic dependence on $Q$. At first glance the linear $Q$ dependence of $\Omega_{\mathrm{s}}$ and the quadratic $Q$ dependence of $\Gamma_{\mathrm{s}}$ are reminiscent of hydrodynamic behaviour. However, in the hydrodynamic limit the measured values of $\Gamma_{s}$ would correspond to longitudinal viscosities more than a factor of ten below the measured macroscopic values [23]. Furthermore, the $\Gamma_{\mathrm{s}}$ increases with temperature (inset to figure 4) while the macroscopic viscosity should decrease. These observations, in addition to the arguments given in the last section, led to the use of the viscoelastic model to describe the results.

In addition to the quadratic $Q$ dependence of $\Gamma_{\mathrm{s}}$, the viscoelastic model could be fitted for the $Q$ values up to $Q=6 \mathrm{~nm}^{-1}$ with a linear $\Delta(Q)$ and a constant $\tau$, so that the longitudinal viscosity, $\eta_{1}(Q)$ in equation (6), became a constant at each temperature. Moreover, the magnitudes were in reasonable agreement with the macroscopic shear viscosity measurements (taking the factor of approximately $7 / 4$ into account) and, like those, decreased with the increasing temperature.

Proceeding to the higher $Q$ values, figure 5 compares the width of the scattering, now only a single peak, with the simple diffusion expression $\Gamma(Q)=D Q^{2}$ and with the kinetic theory prediction of equation (7). The latter is found to give a reasonable description of the $Q$ dependence around the peak in the structure factor at $20 \mathrm{~nm}^{-1}$ and the temperature dependence at the single $Q$ point measured.

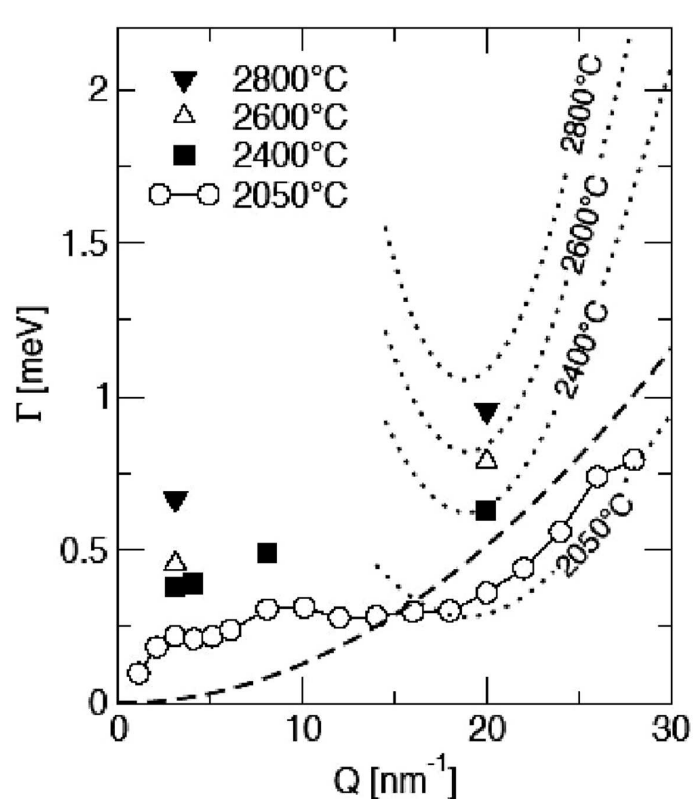

Figure 5. Dependence on wave vector $Q$ of the half-width $\Gamma$ of the Rayleigh peak at different temperatures. The solid line joining the points at $2050^{\circ} \mathrm{C}(2323 \mathrm{~K})$ is a guide to the eye. The dashed line represents $D_{\mathrm{Al}} Q^{2}$ and the dotted lines show predictions based on kinetic theory, equation (7) [9].

\subsection{Liquid $\mathrm{MgAl}_{2} \mathrm{O}_{4}$ and $\mathrm{MgAl}_{4} \mathrm{O}_{7}$}

Pozdnyakova et al. [24] have reported the composition dependence of the microscopic dynamics of the liquid refractory system $\mathrm{MgO}-\mathrm{Al}_{2} \mathrm{O}_{3} \cdot \mathrm{MgAl}_{2} \mathrm{O}_{4}\left(50 \mathrm{~mol} . \% \mathrm{Al}_{2} \mathrm{O}_{3}\right)$ and $\mathrm{MgAl}_{4} \mathrm{O}_{7}(67 \mathrm{~mol} . \%$ $\left.\mathrm{Al}_{2} \mathrm{O}_{3}\right)$ powders were prepared by a sol-gel process, and small pieces of the ingots were melted in a levitation apparatus to obtain homogeneous samples of spherical shape, 2.0 and $2.7 \mathrm{~mm}$ in diameter. The samples were levitated with an oxygen/helium gas jet, in a helium atmosphere to 
decrease the background scattering, and heated by a $125-\mathrm{W} \mathrm{CO}_{2}$ laser beam. The IXS experiments were carried out at the ID16 beamline at European Synchrotron Radiation Facility, Grenoble, France [25]. The $(11,11,11)$ reflection of a Si crystal provided an incident beam with energy of $21.7 \mathrm{keV}$ and $1.5 \mathrm{meV}$ resolution with Lorentzian shape. Four positions of the horizontal arm, containing five backscattering analyzers, were used to obtain 20 constant- $Q$ spectra over the $Q$ range $1-15 \mathrm{~nm}^{-1}$. All spectra were taken at $2423 \pm 10 \mathrm{~K}$. A triplet structure was observed at the lower $Q$ values, though not as well resolved as in the pure $\mathrm{Al}_{2} \mathrm{O}$.

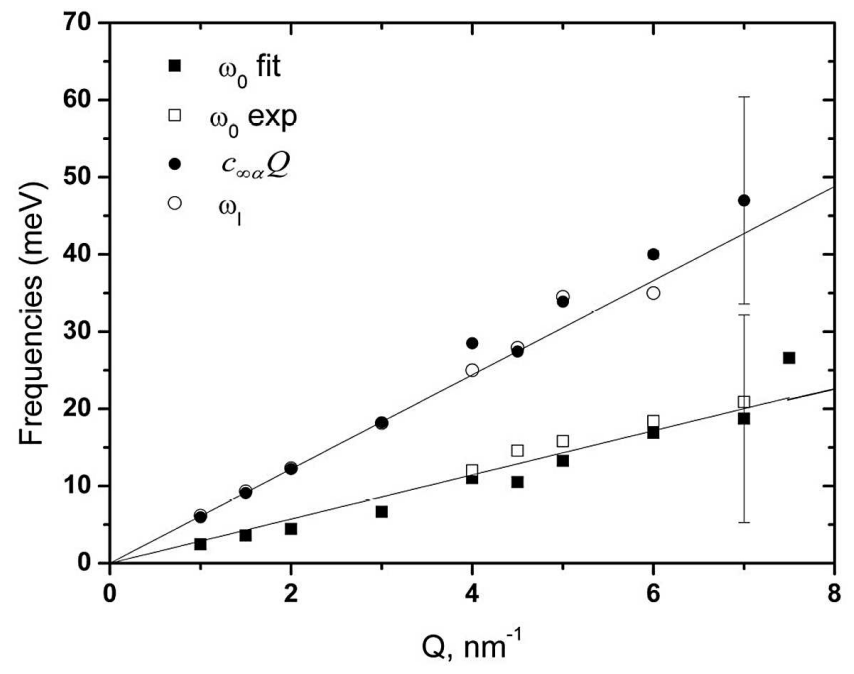

Figure 6. Q dependence of the second frequency moment $\omega_{0}$ derived from the experimental $\mathrm{S}(\mathrm{Q})$ and from the fitting parameters of the viscoelastic model; maxima of the longitudinal current correlation $\omega_{1}$, and the high-frequency limit for structural relaxation $c_{\infty \alpha} \mathrm{Q}$ for $\mathrm{MgAl}_{2} \mathrm{O}_{4}$. The solid lines are linear fits. The errors are calculated from the least square fits to the scattered intensity [24].

The values of $\omega_{0}(Q)$ obtained from a viscoelastic model fit and from available experimental values of $S(Q)[26,27]$ for the case of $\mathrm{MgAl}_{2} \mathrm{O}_{4}$ are shown in figure 6 as closed and open squares, respectively. The closeness of the two sets of values supports the validity of the model. The same figure shows the calculated acoustic dispersion relation $\omega_{l}(Q)$ as open circles, where $\omega_{\mathrm{l}}$ is taken as the position of the maximum of the longitudinal current correlation spectrum $J_{1}(Q, \omega)=\omega^{2} / Q^{2} S(Q, \omega)$, while the values of the excitation frequencies $\Omega_{\mathrm{s}}(Q)$ calculated from equation (5), are shown as closed circles. These two sets of values are also seen to be in close agreement. The linear fit gives values for the longitudinal sound velocity of $9270 \pm 160 \mathrm{~m} / \mathrm{s}$ and $9640 \pm 220 \mathrm{~m} / \mathrm{s}$ for $\mathrm{MgAl}_{2} \mathrm{O}_{4}$ and $\mathrm{MgAl}_{4} \mathrm{O}_{7}$, respectively. A similar analysis of the results for $\mathrm{Al}_{2} \mathrm{O}_{3}$ [9] gave $10050 \pm 250 \mathrm{~m} / \mathrm{s}$. Thus, the values of longitudinal sound velocity increase with increasing $\mathrm{Al}_{2} \mathrm{O}_{3}$ content as for solid oxides [28].

Table 1. The longitudinal viscosity $\left(\eta_{1}\right)$ and structural relaxation time $\left(\tau_{\alpha}\right)$ for liquid oxides at $Q=2 \mathrm{~nm}^{-1}$ and $2423 \mathrm{~K}[24]$.

\begin{tabular}{|l|l|l|l|}
\hline \multirow{2}{*}{ Material } & $\eta_{\mathrm{l}}, \mathrm{mPa} \cdot \mathrm{s}$ & $\tau_{\alpha}, \mathrm{ps}$ \\
\cline { 2 - 4 } & $\exp$ & $\mathrm{MD}$ & $\exp$ \\
\hline $\mathrm{Al}_{2} \mathrm{O}_{3}[9]$ & 60 & $45 \pm 2$ & 0.5 \\
\hline $\mathrm{MgAl}_{4} \mathrm{O}_{7}$ & $80 \pm 12$ & $51 \pm 4$ & $1.15 \pm 0.1$ \\
\hline $\mathrm{MgAl}_{2} \mathrm{O}_{4}$ & $60 \pm 6$ & $45 \pm 2$ & $0.9 \pm 0.1$ \\
\hline
\end{tabular}

As in the case of pure liquid $\mathrm{Al}_{2} \mathrm{O}_{3}$, the values of the generalized longitudinal viscosity $\eta_{1}(Q)$ and relaxation time $\tau$ derived from the viscolelastic model fits did not change significantly with $Q$. 
Values for $\mathrm{MgAl}_{2} \mathrm{O}_{4}$ and $\mathrm{MgAl}_{4} \mathrm{O}_{7}$ at $Q=2 \mathrm{~nm}^{-1}$ are given in table 1, along with those for $\mathrm{Al}_{2} \mathrm{O}_{3}$ interpolated to $2423 \mathrm{~K}$ from [9]. The table also shows the longitudinal viscosity obtained with a molecular dynamics (MD) simulations using an advanced ionic interaction potential [29] that has been shown to reproduce well the structure factor, scattering function, self-diffusion coefficient and longitudinal viscosity of molten $\mathrm{Al}_{2} \mathrm{O}_{3}[30]$ and was here extended to the ternary system. Both experiment and simulation show a weak maximum in the viscosity around the $\mathrm{MgAl}_{4} \mathrm{O}_{7}$ composition. The self-diffusion coefficients of $\mathrm{Al}^{3+}$ and $\mathrm{O}^{2-}$ ions obtained from the simulation showed a minimum at the same compiston while the mobility of $\mathrm{Mg}^{2+}$ ions decreased steadily with increasing $\mathrm{Mg}$ content. It appears that addition of relatively small amounts of $\mathrm{MgO}$ to $\mathrm{Al}_{2} \mathrm{O}_{3}$ melt stabilizes the $\left[\mathrm{AlO}_{4}\right]^{5-}$ network.

\section{Liquid metals}

Inelastic neutron and x-ray scattering experiments on liquid metals have recently been reviewed by Scopigno et al. [31]. Here we discuss two systems studied at high temperature using levitation techniques.

\subsection{Supercooled liquid and hot solid silicon}

In addition to the advantages of eliminating contamination and scattering from the sample container, levitation provides the capability for substantial undercooling, due to the elimination of most of the heterogeneous nucleation. A case of particular interest is silicon, both due to its importance in the semiconductor industry - crystalline silicon is normally generated from the melt and amorphous silicon is made from slightly supercooled melts - and due to the conjecture of Angell and Borick [32], further developed by Sastry and Angell [33] and Mirandi and Antonelli [34], of a first-order liquid-liquid transition at a temperature close to the experimentally observed supercooling limit.

In the crystalline phase at ambient conditions, silicon is a diamond-structured semiconductor but on melting it undergoes a semiconductor-to-metal transition accompanied by significant changes in the structure and density. The coordination number increases from 4 in the solid to about 6.5 in the liquid [35] and the liquid density is increased by about 10\% [36]. In addition, the experimental structure factor $S(Q)$ of liquid silicon shows a distinct characteristic feature around the first maximum. In the stable liquid phase, the main peak has a shoulder on the high-Q side, which becomes resolved into a second peak as the temperature decreases into supercooled regime [37]. The main features of the diffraction patterns are successfully reproduced by ab-initio molecular dynamics calculations $[35,37]$. The sharpening of the shoulder, reduction in coordination number to about 5.5 and an increase in the amplitude of the maximum in the bond-angle distribution close to the tetrahedral angle, all indicate that the tetrahedral ordering is reinforced in the supercooled regime [37], supporting the conjecture of Angell and Borick.

The scattering function of normal liquid silicon was measured using IXS technique by Hosokawa et al., with a resistance heater in a vessel, providing experimental evidence of a propagating sound mode [38]. More recently, the scattering function of the supercooled liquid silicon at $1620 \mathrm{~K}$ (65 K below the equilibrium melting point) was measured by Alatas et al. using IXS in conjunction with aerodynamic levitation [39]. The hot solid was also measured at the same temperature. The measurements were made at the APS using the spectrometer and levitation system described above for $\mathrm{Al}_{2} \mathrm{O}_{3}$.

Excitation frequencies were obtained for the supercooled liquid with the procedure also described there, and for the hot solid by fitting a single Lorentzian to the well-defined longitudinal phonon peaks. Longitudinal sound velocities obtained from the initial slopes of the dispersion curves of excitation frequency vs. $Q$ are shown in figure 7 . Also shown are the velocities obtained from the elastic modulus data of Nikanorov et al. [40], extrapolated beyond the temperature limit of their measurements, $870 \mathrm{~K}$. At $1620 \mathrm{~K}$ the value obtained from the IXS results for the hot solid are $9 \%$ lower than this extrapolation, for reasons not yet understood. The IXS results show a $40 \%$ drop in longitudinal sound velocity on melting, which, as already discussed, is accompanied by a 
semiconductor-metal transition, and a further $4 \%$ on heating to the normal liquid at $1733 \mathrm{~K}$ [38], which could be a further reflection of the increase in tetrahedral character on supercooling, as also discussed above.

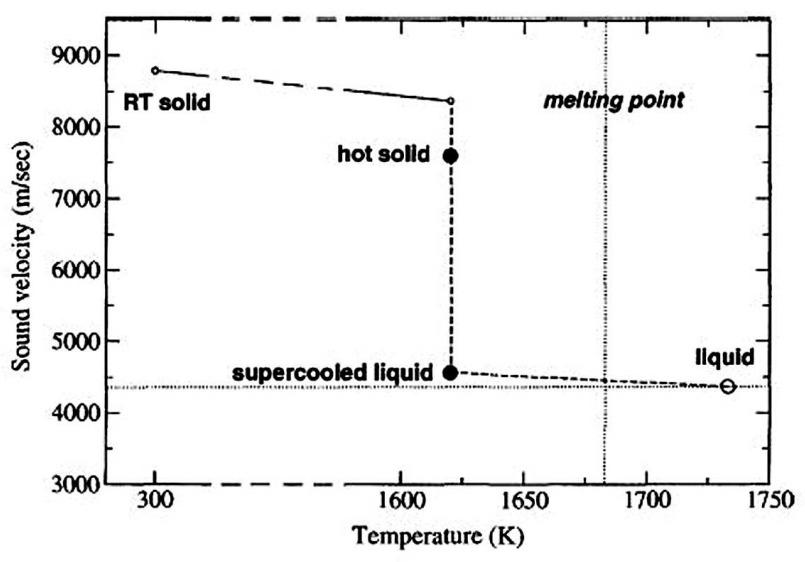

Figure 7. Sound velocities for supercooled liquid and hot solid silicon measured from this experiment together with average values for solid between room temperature and $1620 \mathrm{~K}$ calculated from reference [40] through the longitudinal modulus and the liquid sound velocity from reference [38], [39].

\subsection{Liquid titanium}

Transition metals are clearly attractive materials for studying liquid dynamics since the interatomic potential can be considered to the lowest approximation as a hard-core potential. For obvious practical reasons, most IXS studies so far have been carried out on mercury in the normal [41] and expanded [42] fluid states. To our knowledge the only investigation of a transition metal with IXS at high temperature is that of Said et al. [43] on liquid titanium. IXS measurements

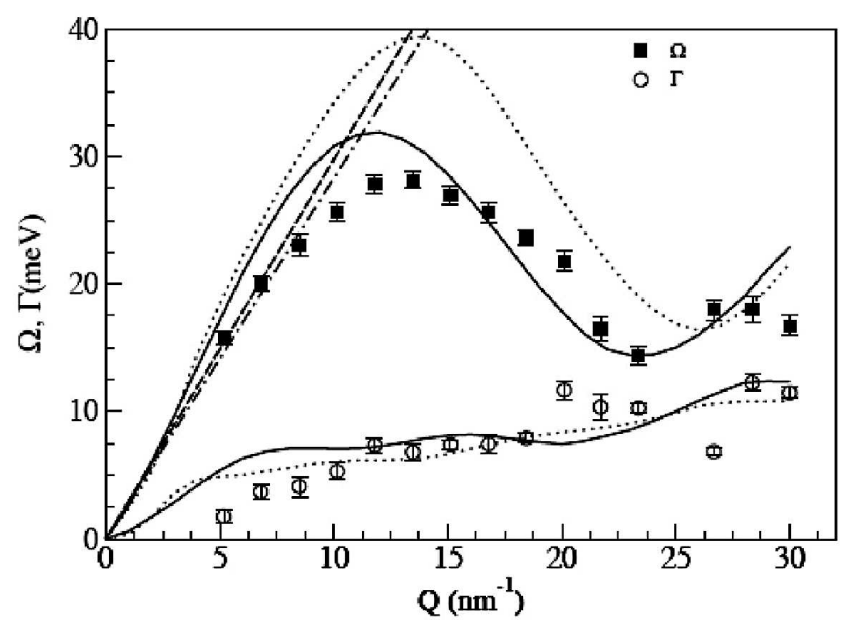

Figure 8. Frequencies (closed symbols) and half-widths (open symbols) of the sound excitations in liquid Ti. The solid lines are the MCT calculations using the structure factor of Waseda [53], and the dotted lines that of Lee et al. [54], [43].

were made at $2020 \mathrm{~K}$, just above the melting point. The experimental setup was again the one used for $\mathrm{Al}_{2} \mathrm{O}_{3}$. As with the silicon measurement described above, high-purity argon gas, passed 
through a purifier, was used as the levitating medium, and the sample chamber was purged several times before the final evacuation and levitation measurements. Excitation frequencies $\Omega_{\mathrm{s}}$ and half-widths $\Gamma_{\mathrm{s}}$ derived using the same procedure as in the liquid $\mathrm{Al}_{2} \mathrm{O}_{3}$ experiments are shown in figure 8 . The linear $Q$ dependence of the dispersion corresponds to a longitudinal sound velocity $c=4520 \pm 50 \mathrm{~m} / \mathrm{s}$, about $2.5 \%$ higher than the adiabatic sound velocity [44] as shown by the dashed-dotted line in figure 2. The damping of the excitations is comparable to that of liquid lithium [45,46] and liquid nickel [47]. The curves represent theoretical calculations described below. In these measurements it was possible to measure the central peak at $Q$ values above $5 \mathrm{~nm}^{-1}$, in which case it was possible to directly extract a generalized longitudinal viscosity as $[48,49]$

$$
\eta_{1}(Q)=\pi \rho v_{0}^{2} \frac{S(Q, 0)}{S(Q)^{2}}
$$

The values obtained in this way are plotted in figure 9 , and the width $\Gamma_{0}$ of the central peak in figure 10. The curves again represent theoretical calculations.

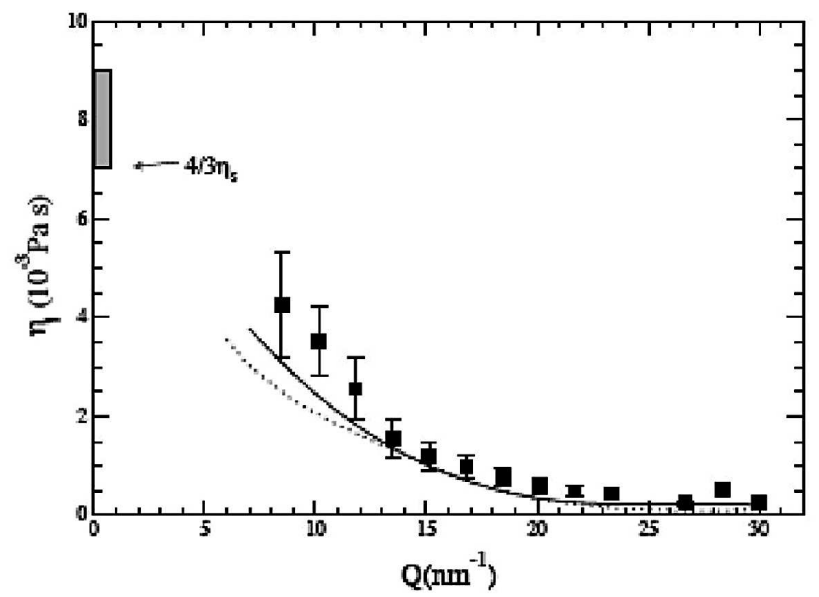

Figure 9. The longitudinal viscosity as a function of $Q$. The values for $4 / 3 \eta_{\mathrm{s}}\left(\eta_{\mathrm{s}}\right.$ is the shear viscosity) and the expected range of the longitudinal viscosity at $Q=0$ are marked [W. F. Gale and T. C. Totemier, Smithells Metals Reference Book (Elsevier Butterworth, Heinemann, Amsterdam, 2004)]. The lines have the same notation as figure 8 [43].

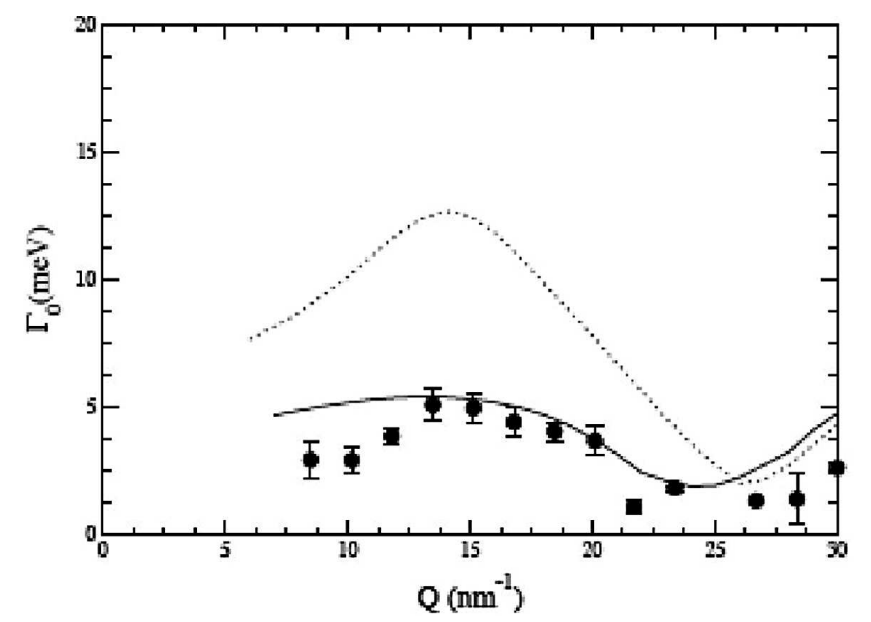

Figure 10. The half-width of the central peak as a function of $Q$. The lines have the same notation as figure 8 [43]. 
One of the most successful approaches to a microscopic description of liquid dynamics, as well as the approach to the glass transition, is mode-coupling theory (MCT). In its original version $[49,50]$ the memory functions for the current fluctuation spectra were related to the modes of density and current correlations. Subsequently, a much simpler version [51,52] was found to successfully describe the relaxation processes in the vicinity of the glass transition. In this form the structure factor $S(Q)$ and the number density $\rho$ are the only inputs. Said et al. used this theory to calculate the intermediate scattering function $F(Q, t)$. For the structure factor they used two different data sets, one from Waseda [53] at $T=1975 \mathrm{~K}$ and the other from Lee et al. [54] at $T=1985 \mathrm{~K}$, which were extrapolated to the isothermal compressibility at low $Q$.

The values of $F(Q, t)$ were Fourier transformed to obtain the scattering function $S(Q, \omega)$, which was then fitted with the same three-Lorentzian function used in order to fit the experimental data. The results are shown by solid lines (Lee et al. $S(Q)$ ) and by dotted lines (Waseda $S(Q)$ ) in figures $8-10$.

The difference in the two sets of curves indicates that the current level of accuracy of $S(Q)$ measurements in this $Q$ range is not sufficient to predict the dispersion precisely. Nevertheless, the agreement of the mode-coupling calculations with the experimental data, especially those made with the Waseda $S(Q)$, is quite impressive. The damping of the sound modes, shown as open symbols in figure 8 , and the $Q$-dependent viscosity shown in figure 3 , shows excellent agreement with both calculations. This indicates that the damping of the low- $Q$ sound modes is dominated by the height and the width of the first peak of the $S(Q)$, rather than the detailed behaviour of $S(Q)$ at lower and higher $Q$. The fact that the simplified mode-coupling approximation, using just the decay into two longitudinal modes and neglecting the coupling to transverse modes, gives a good description of the sound damping suggests that the cage effect that produces the glassy arrest at high densities also dominates in the less viscous, liquid regime.

\section{Conclusions}

The use of aerodynamic levitation combined with laser heating presents a relatively simple and versatile approach to the study of the microscopic dynamics of high-temperature molten oxides and metals, following its successful application to the structural studies and electrodeless measurements of conductivity and other physical properties. With improvements in instrumentation now being made, it should be possible to study the changes in dynamics in real time during cooling toward and through the glass and freezing transitions.

\section{Acknowledgements}

The authors wish to thank their many colleagues who made the work reviewed here possible. Helpful discussions with C. A. Angell are gratefully acknowledged. This work was supported by the CNRS and the Regional Council of the Région Centre. 


\section{References}

1. Egelstaff P.A. An Introduction to the Liquid State. Clarendon Press, Oxford, 1992.

2. Balucani U., Zoppi M. Dynamics of the Liquid State, Clarendon Press, Oxford, 1994.

3. Scopigno T., Ruocco G., Sette F., Rev. Mod. Phys., 2005, 77, 881.

4. Monaco G., Cunsolo A., Ruocco G., Sette F., Phys. Rev. E, 1999, 60, 5505.

5. Angelini R., Guira P., Fioretto D., Monaco G., Ruocco G., Sette F., Phys. Rev. B, 2004, 70, 224302.

6. Cunsolo A., Pratesi G., Verbeni R., Colognesi D., Monaco G., Masciovecchio C., Ruocco G., Sette F., J. Chem. Phys., 2001, 114, 2259.

7. Krishnan S., Price D.L., J. Phys.: Condens. Matter, 2000, 12, R145-176.

8. Hennet L., Thiaudiere D., Gailhanou M., Landron C., Coutures J.-P., Price D.L., Rev. Sci. Instrum., 2002, 73, 124 .

9. Sinn H., Glorieux B., Hennet L., Alatas A., Hu M., Alp E.E., Bermejo F.J., Price D.L., Saboungi M.-L., Science, 2003, 299, 2047.

10. Price D.L., Saboungi M.-L., Bermejo F.J., Rep. Prog. Phys., 2003, 66, 407-480.

11. Sette F., Ruocco G., Krisch M., Bergmann U., Masciovecchio C., Mazzacurati V., Signorelli G., Verbeni R., Phys. Rev. Lett., 1995, 75, 850-853.

12. Burkel E., Rep. Prog. Phys., 2000, 63, 171.

13. Sinn H., J. Phys.: Condens. Matter, 2001, 13, 7225.

14. Price D.L., Skold K. - In Methods of Experimental Physics, vol. 23, Neutron Scattering Part A. Academic Press Inc., 1986.

15. Mountain R., J. Res. Nat. Bur. Stand. A, 1966, 70, 207.

16. Harrison G. The dynamical properties of supercooled liquids. Academic, New York, 1976.

17. Cohen E.G.D., Westerhuijs P., de Schepper I.M., Phys. Rev. Lett., 1987, 59, 2872.

18. Saboungi M.-L., Enderby J., Glorieux B., Schnyders H., Sungaila Z., Krishnan S., Price D.L., J. NonCryst. Solids, 2002, 312-314, 294-298.

19. Ansell S. et al., Phys. Rev. Lett. , 1997, 78, 464.

20. Landron C. et al., Phys. Rev. Lett., 2001, 86, 4839.

21. Schober H., Strauch D., Dorner B., Z. Phys. B: Condens. Matter, 1993, 92, 273.

22. Castanet R., High Temp. High Press., 1984, 16, 449.

23. Urbain G., Rev. Int. Hautes Temp. Refract. (Paris), 1982, 19, 55.

24. Pozdnyakova I., Hennet L., Brun J.-F., Zanghi D., Brassamin S., Cristiglio V., Price D.L., Albergamo F., Bytchkov A., Jahn S., Saboungi M.-L., J. Chem. Phys., 2007, 126, 114505.

25. Verbeni R., Sette F., Krisch M.H., Bergmann U., Gorges B., Halcoussis C., J. Synch. Rad., 1996, 3, 62.

26. Hennet L., Pozdnyakova I., Cristiglio V., Krishnan S., Bytchkov A., Albergamo F., Cuello G., Brun J.F., Fischer H.E., Zanghi D., Brassamin S., Saboungi M.-L., Price D.L., J. Non-Cryst. Solids, 2007, 352, 1705-12.

27. Hennet L., Pozdnyakova I., Cristiglio V., Cuello G.J., Jahn S., Krishnan S., Saboungi M.-L., Price D.L., J. Phys.: Condens. Matter, 2007, 19, 455210.

28. Landolt-Börnstein. New series, Group V, Vol. 1, subvol. B. Springer-Verlag, Berlin-Heidelberg, 1982.

29. Jahn S., Madden P.A., Wilson M., Phys. Rev. B, 2004, 69, 020106(R).

30. Jahn S., Madden P.A., J. Non-Cryst. Solids, 2007, 353, 3500.

31. Scopigno T., Ruocco G., Sette F., Rev. Mod. Phys., 2005, 77, 881.

32. Angell C.A., Borick S.S., J. Phys. Cond. Matt., 1999, 11, 8163.

33. Sastry S., Angell C.A., Nat. Mater., 2003, 2, 739.

34. Miranda C.R., Antonelli A., J. Chem. Phys., 2004, 120, 11672.

35. Jaske N. et al., Phys. Rev. B, 2000, 61, 14287.

36. Ohsaka K. et al., Appl. Phys. Lett., 1997, 70, 423.

37. Jakse N., Krishnan S., Artacho E., Key T., Hennet L., Glorieux B., Pasturel A., Price D.L., Saboungi M.-L., Appl. Phys. Lett., 2003, 83, 4374-6.

38. Hosokawa S. et al., J. Phys.: Condens. Matter, 2003, 15, L623.

39. Alatas A., Said A.H., Sinn H., Alp E.E., Kodituwakku C.N., Reinhart B., Saboungi M.-L., Price D.L., J. Phys. Chem. Solids, 2005, 66, 2230-4.

40. Nikanorov S.P. et al., Phys. Solid State, 1971, 13, 2516.

41. Hosokawa S., Sinn H., Hensel F., Alatas A., Alp E.E., Pilgrim W.-C., J. Non-Cryst. Solids, 2002, 312-314, 163.

42. Ishikawa D., Inui M., Matsuda K., Tamura K., Tsutsui S., Baron A.Q.R., Phys. Rev. Lett., 2004, 93, 097801. 
43. Said A.H., Sinn H., Alatas A., Burns C.A., Price D.L., Saboungi M.L., Schirmacher W., Phys. Rev. B, 2006, 74, 172202 .

44. Casas J., Keita N.M., Steinemann S.G., Phys. Chem. Liq., 1984, 14, 155.

45. Sinn H., Sette F., Bergmann U., Halcoussis C., Krisch M., Verbeni R., Burkel E., Phys. Rev. Lett., 1997, 78, 1715.

46. Scopigno T., Balucani U., Ruocco G., Sette F., Phys. Rev. Lett., 2000, 85, 4076.

47. Bermejo F.J., Saboungi M.L., Price D.L., Alvarez M., Roessli B., Cabrillo C., Ivanov A., Phys. Rev. Lett., 2000, 85, 106.

48. Kugler A.A., J. Stat. Phys., 1973, 8, 107.

49. Bosse J., Götze W., Lücke M., Phys. Rev. A, 1978, 17, 434.

50. Götze W., Lücke M., Phys. Rev. A, 1975, 11, 2173.

51. Bengtzelius U., Götze W., Sjolander A., J. Phys. C, 1984, 17, 5915.

52. Götze W., Mayr M.R., Phys. Rev. E, 2000, 61, 587.

53. Waseda Y. The Structure of Non-Crystaline Materials. McGraw-Hill, New York, 1980.

54. Lee G.W., Gangopadhyay A.K., Kelton K.F., Hyers R.W., Rathz T.J., Rogers J.R., Robinson D.S., Phys. Rev. Lett., 2004, 93, 037802.

\title{
Динаміка нанометрового масштабу у високотемпературних левітованих рідинах
}

\author{
Д.Л.Прайс ${ }^{1}$, л.Хеннет ${ }^{1}$, І.Позднякова ${ }^{1}$, М.-Л.Сабунґі' \\ 1 Центр досліджень матеріалів при високих температурах, Орлеан, Франція \\ 2 Центр досліджень подрібненої матерії, Орлеан, Франція \\ Отримано 16 листопада 2007 р.
}

\begin{abstract}
Ми робимо огляд недавніх досліджень мікроскопічної динаміки високотемпературних рідин, зроблених з непружнім розсіянням рентгенівських променів та аеродинамічною левітацією зразків. Обговорюються також феноменологічні та теоретичні інтепретації.
\end{abstract}

Ключові слова: динаміка рідин, розплави оксидів, рідкі метали, непружнє розсіяння рентгенівських променів, аеродинамічна левітація

PACS: $66.20 .+d, 61.10 . E q$ 
